\title{
Can Anti-Müllerian Hormone Be a Reliable Biomarker for Assessing Ovarian Function in Women Postchemotherapy?
}

This article was published in the following Dove Press journal: Cancer Management and Research

\author{
Xiaolin $\mathrm{Li}^{1,2, *}$ \\ Sixuan Liu ${ }^{1, *}$ \\ Lisi Ma' \\ Xuan Chen' \\ Huaiyu Weng' \\ Run Huang' \\ Yang $\mathrm{Yu}^{2}$ \\ Xiangyun Zong' \\ 'Department of Breast Surgery, Shanghai \\ Jiao Tong University Affiliated Shanghai \\ Sixth People's Hospital, Shanghai 200233, \\ People's Republic of China; ${ }^{2}$ Institute of \\ Cancer and Basic Medicine, Cancer \\ Hospital of the University of Chinese \\ Academy of Science (Zhejiang Cancer \\ Hospital), Hangzhou 310022, People's \\ Republic of China
}

*These authors contributed equally to this work
Correspondence: Xiangyun Zong Department of Breast Surgery, Shanghai Jiao Tong University Affiliated Sixth People's Hospital, Shanghai 200233, People's Republic of China

Tel +86 2I 24058549

Email tigerzong@msn.com
Purpose: The predictive value of anti-Müllerian hormone (AMH) for ovarian dysfunction postchemotherapy is controversial. This study aimed to evaluate the value of serum AMH levels clinically and theoretically.

Patients, Animals, and Methods: We detected the serum estradiol, follicular stimulating hormone (FSH), luteinizing hormone ( $\mathrm{LH})$, and AMH levels in 144 premenopausal women with breast cancer receiving cyclophosphamide-based chemotherapy. The hormone levels before and postchemotherapy were compared; the correlations among the hormones and amenorrhea and menstrual recovery were analyzed. In addition, the serum $\mathrm{AMH}$ levels were detected randomly in 177 normal healthy women and 36 normal female C57BL/6J mice of different ages; meanwhile, the status of ovarian follicles was also examined. Furthermore, $72 \mathrm{Balb} / \mathrm{c}$ nude mice with breast cancer were randomly assigned to three groups that received different doses of cyclophosphamide (CTX) (control, $100 \mathrm{mg} / \mathrm{kg}$, and $200 \mathrm{mg} / \mathrm{kg}$ ), and the alterations in serum AMH levels and ovarian follicles were recorded and analyzed.

Results: Chemotherapy-induced amenorrhea was associated with prechemotherapy AMH levels, E2 levels, and FSH levels $(P<0.0001)$. The recovery of menstruation was associated with prechemotherapy AMH levels $(P<0.0001)$, but not with E2 and FSH levels $(P>0.05)$. In patients with breast cancer treated with chemotherapy, the serum AMH levels did not differ significantly between the pre- and post-chemotherapy periods in patients aged $<35$ years $(P>0.05)$, whereas a dramatic reduction was detected in patients aged $>35$ years $(P<$ 0.0001). In healthy women, the serum AMH levels declined sharply after 35 years of age $(P<0.0001)$ and remained relatively stable at a younger age. Similar results were obtained in experiments using normal mice. The cancer-bearing mice exposed to $200 \mathrm{mg} / \mathrm{kg}$ CTX exhibited a significant decline in AMH levels and a remarkable decrease in the number of primordial and growing follicles $(P<0.0001)$.

Conclusion: Our results indicate that AMH is an efficient marker for predicting postchemotherapy ovarian function exclusively in premenopausal female patients with breast cancer aged $>35$ years.

Keywords: anti-Müllerian hormone, ovarian function, cyclophosphamide, breast cancer

\section{Introduction}

Anti-Müllerian hormone $(\mathrm{AMH})$, which is a dimeric glycoprotein of $140 \mathrm{kDa}$ belonging to the transforming growth factor- $\beta$ superfamily, is composed of two identical subunits and is also called Müllerian-inhibiting substance (MIS). ${ }^{1,2}$ Moreover, $\mathrm{AMH}$ is secreted by the ovarian granulosa cells of females from 36 
weeks of gestation until menopause. ${ }^{3}$ Its expression begins in the primary follicles and peaks in the secondary and small antral follicles but is not detected in primordial follicles and atretic follicles. ${ }^{4,5}$ It has an inhibitory role in the recruitment and development of the primordial follicles into growing follicles. ${ }^{6,7}$ Previous investigations have validated the serum AMH level as a quantitative marker of ovarian reserve and ovarian dysfunction in in vitro fertilization (IVF) and polycystic ovary syndrome. ${ }^{8-10}$ However, the role of AMH in predicting the recovery of ovarian function in postchemotherapy patients remains controversial.

Chemotherapeutic regimens including gonadotoxic molecules are usually used to treat younger patients with advanced malignancies, ${ }^{11-13}$ whereas cyclophosphamide (CTX) is one of the most used cell-cycle nonspecific cytotoxic drugs and frequently causes ovarian function damage. ${ }^{14}$ Ovarian toxicity due to CTXbased chemotherapy usually manifests as amenorrhea or even premature ovarian failure (POF). ${ }^{15}$ Many serum markers, such as follicular stimulating hormone (FSH), luteinizing hormone ( $\mathrm{LH}$ ), inhibin $\mathrm{B}$, and $\mathrm{AMH}$, have been employed to evaluate the ovarian reserve and the ability to conceive. ${ }^{16-19}$ As AMH is relatively stable and is not affected by the menstrual cycle, ${ }^{20}$ many studies have adopted AMH as a prominent biomarker to assess ovarian function during the postchemotherapy follow-up period. ${ }^{21-24}$ However, the results of those studies were contradictory, and no consensus has been reached to date regarding the predictive value of AMH for ovarian function after chemotherapeutic damage. . $1,22,25,26^{-26}$

Considering the controversial issues mentioned above, this study was performed to examine whether AMH is an effective biomarker for predicting ovarian function in premenopausal female patients with breast cancer receiving chemotherapy and to identify the patients in whom the serum AMH level is the most valuable predictor of ovarian function.

\section{Patients, Animals, and Methods Study Population}

From January 2016 to December 2017, we randomly recruited 144 premenopausal women with breast cancer (age, 27-49 years; median, 43 years) who required postoperative chemotherapy at our breast center. The regimens used were TEC (docetaxel $75 \mathrm{mg} / \mathrm{m}^{2}+$ epirubicin $60 \mathrm{mg} / \mathrm{m}^{2}+$ CTX $500 \mathrm{mg} / \mathrm{m}^{2}$, D1) or FEC (5-fluorouracil $500 \mathrm{mg} / \mathrm{m}^{2}+$ epirubicin $75 \mathrm{mg} / \mathrm{m}^{2}+$ CTX $500 \mathrm{mg} / \mathrm{m}^{2}$, D1) every 3 weeks for a total of six cycles. Patients with previous chemotherapy for malignancy or other diseases or with comorbidities related to fertility and patients with breast cancer treated without chemotherapy were excluded. The serum E2, FSH, LH, and $\mathrm{AMH}$ levels were detected twice in the patients with breast cancer: before chemotherapy and at 6 months after the last injection of chemotherapy. In this study, amenorrhea was defined as the disappearance of the menstrual cycle during chemotherapy or postchemotherapy for 6 months; if the menstruation appeared periodically again within 1 year postchemotherapy, the state of the women was defined as "recovery of menstruation". ${ }^{27}$ The changes in menstruation postchemotherapy were followed-up.

Concomitantly, 177 normal healthy women (age, 17-75 years; median, 44 years) without a history of gynecological disease or any cancer were recruited into the study, and the serum AMH level of individuals was detected randomly. Written informed consent was obtained from all participants, and ethical approval was granted by the Ethics Committee of Shanghai Jiao Tong University Affiliated Sixth People's Hospital.

\section{Animals}

This project was approved by the Animal Ethics and Welfare Committee of Shanghai Jiao Tong University Affiliated Sixth People's Hospital and performed in accordance with the Animal Research: Reporting of in vivo Experiments (ARRIVE) guidelines. Blood was collected from the heart of 36 young female wild-type C57BL/6J mice aged 1, 4, 6, 8, 12, and 16 months (six mice per age group) at the time of euthanasia, and their ovaries were removed for further tests.

In addition, 72 young female inbred Balb/c nude mice (obtained from Shanghai SLAC Laboratory Animal Co., Shanghai, China) aged 6 weeks and weighing $15-20 \mathrm{~g}$ were randomly divided into three groups. MCF7 cells $\left(1 \times 10^{7}\right)$ were injected subcutaneously into all mice in each group. We observed and recorded tumor growth every 2 days. At 8 weeks of age, mice in group $1(n=24)$, group $2(n=24)$, and group $3(n=24)$ were treated with a single intraperitoneal injection of $0.1 \mathrm{~mL}$ of saline, $100 \mathrm{mg} / \mathrm{kg}$ of CTX, and $200 \mathrm{mg} / \mathrm{kg}$ of CTX, respectively. The dosages of CTX were based on 
a previous study that demonstrated a significant dosedependent ovarian toxicity without sterilization. ${ }^{16,28} \mathrm{Six}$ mice selected stochastically from each group underwent heart blood collection at the time of euthanasia (anesthetization and euthanasia by terminal cardiac puncture) and ovary excision before chemotherapy. Moreover, 1, 3 , and 5 weeks postchemotherapy, six mice selected stochastically from each group underwent blood collection before euthanasia and ovary excision at each time point (Figure 1). Ovaries were fixed in formalin, embedded in paraffin, and stained with hematoxylin and eosin (H\&E), while sera were isolated from blood samples, for hormonal measurements.

\section{Serum E2 and FSH Assay}

Serum E2 and FSH in all 144 patients with breast cancer were tested using an ADVIA Centaur XP Immunoassay System (SIEMENS), respectively.

\section{Serum AMH Assay}

Human and mouse serum AMH levels were measured using the Human AMH ELISA kit (Cusabio Biotech,

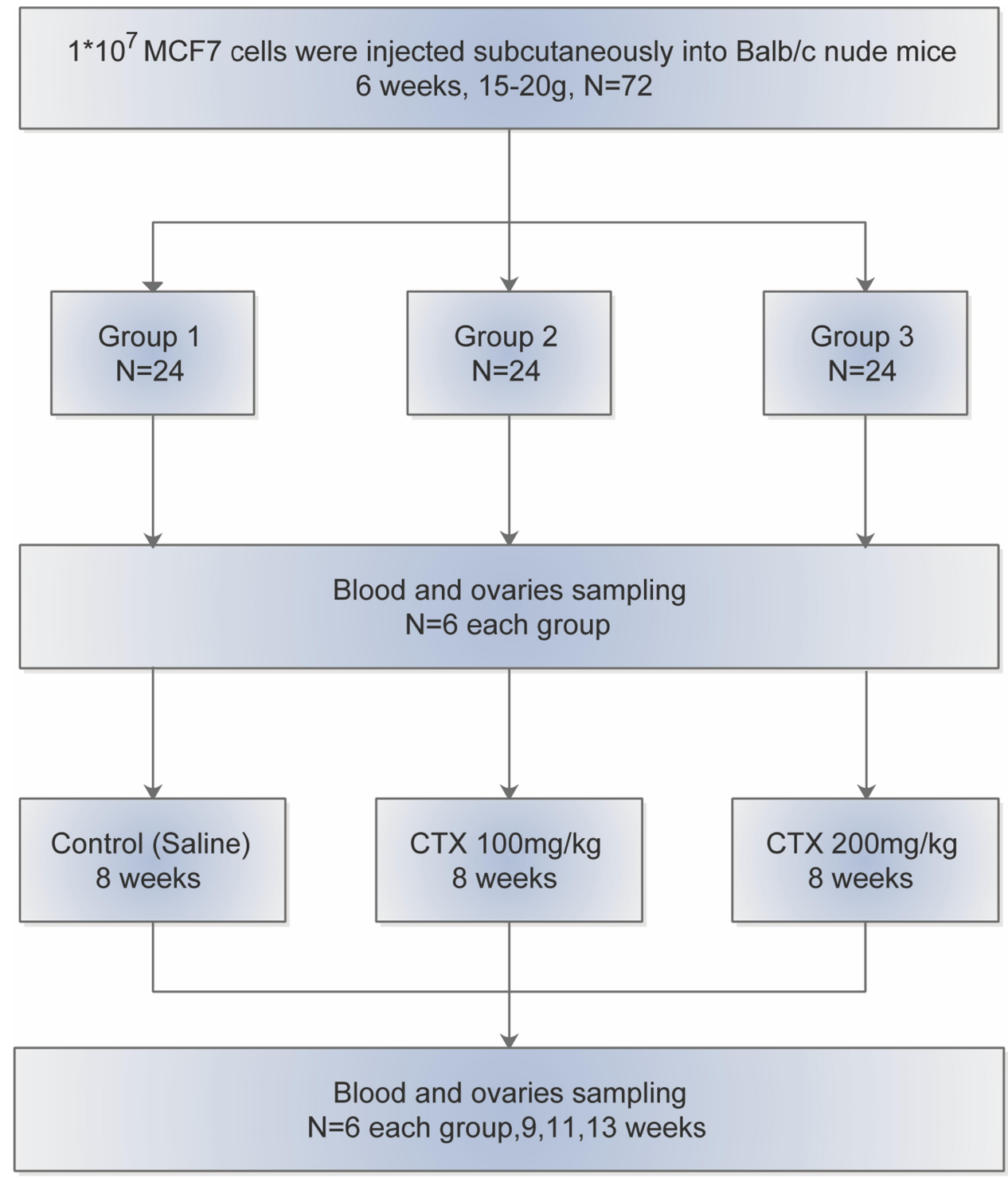

Figure I Flowchart of the experiments performed using cancer-bearing mice. Seventy-two Balb/c nude mice aged 6 weeks and weighing $15-20 \mathrm{~g}$ were randomly divided into three groups. MCF7 cells $\left(1 \times 10^{7}\right)$ were injected subcutaneously into each mouse in all groups. At 8 weeks of age, mice in group I ( $\left.n=24\right)$, group $2(n=24)$, and group $3(n$ $=24$ ) were treated with a single intraperitoneal injection of $0.1 \mathrm{~mL}$ of saline, $100 \mathrm{mg} / \mathrm{kg}$ of CTX, and $200 \mathrm{mg} / \mathrm{kg}$ of CTX, respectively. Six mice that were selected stochastically from each group underwent heart blood collection at the time of euthanasia and ovary excision before chemotherapy. Subsequently, at 9 , II, and I 3 weeks of age, six mice that were selected stochastically from each group underwent blood collection before euthanasia and ovary excision at each time point. 
CATALOG \#:11351) and the Mouse AMH ELISA kit (XLPM0168), respectively. The assays were performed according to the manufacturer's protocol, and the concentrations of AMH were determined from the standard curve. All serum samples were assayed in duplicate.

\section{Follicle Counting}

We counted the follicles as described previously. ${ }^{29}$ Briefly, the total number of follicles in each ovary was estimated by counting the number of follicles in each of five sections of H\&E-stained whole ovaries and applying a 5-fold correction factor. Then, $5 \mu \mathrm{m}$-thick sections were serially cut, and the follicles were counted every fifth section. Each follicle goes through five stages: the primordial, primary, secondary, antral, and corpus luteum stages. Only follicles with an oocyte nucleus were counted. Primary follicles, secondary follicles, and antral follicles were collectively referred to as growing follicles.

\section{Statistical Analysis}

The data were expressed as the mean \pm standard error of the mean. The statistical analysis was performed using the GraphPad Prism 7 and SAS 8.02 software, and differences among the chemotherapy groups and the control group were determined using a one-way analysis of variance, followed by a multiple comparison test. Correlations between menstruation status and hormone levels were assessed using a logistic regression analysis. Statistical significance was set at $P<0.05$.

\section{Results}

\section{Patient Characteristics}

The clinicopathological characteristics of patients with breast cancer are displayed in Table 1. Most of the patients were diagnosed at an age over 35 years $(86.1 \%)$ and were primarily diagnosed with a T1 $(39.6 \%)$ or T2 (44.4\%) tumor. Histological diagnoses comprised invasive duct carcinomas (89.6\%), lobular carcinomas (4.9\%), and others (5.5\%). In this cohort, the molecular subtype in $67(46.5 \%), 41(28.5 \%)$, $12(8.3 \%)$, and $24(16.7 \%)$ patients was HR+/HER2-, HR +/HER 2+, HR-/HER2+, and TNBC, respectively. A total of $12(8.3 \%), 92(63.9 \%)$, and $40(27.8 \%)$ women received total mastectomy, modified radical mastectomy, and breastconserving surgery, respectively.
Table I Clinicopathological Characteristics of the Breast Cancer Patients

\begin{tabular}{|l|l|}
\hline Characteristics & Number of Patients (N= I44) \\
\hline $\begin{array}{l}\text { Age (years) } \\
<35\end{array}$ & $20(13.9 \%)$ \\
$\geq 35$ & $124(86.1 \%)$ \\
\hline T stage & \\
I & $57(39.6 \%)$ \\
3 & $64(44.4 \%)$ \\
4 & $19(13.2 \%)$ \\
\hline Axillary lymph node & $4(2.8 \%)$ \\
Negative & \\
Positive & $94(65.3 \%)$ \\
\hline Histology & $50(34.7 \%)$ \\
Invasive ductal carcinoma & $129(89.6 \%)$ \\
Invasive lobular carcinoma & $7(4.9 \%)$ \\
Others & $8(5.5 \%)$ \\
\hline Grade & \\
I & $35(24.3 \%)$ \\
II & $54(37.5 \%)$ \\
III & $40(27.8 \%)$ \\
undifferentiated & $15(10.4 \%)$ \\
\hline Molecular subtype & \\
HR+/HER2- & $67(46.5 \%)$ \\
HR+/HER2+ & $41(28.5 \%)$ \\
TNBC & $12(8.3 \%)$ \\
\hline Operationed & $24(16.7 \%)$ \\
\hline
\end{tabular}

\section{Menstruation Status and Productive Hormone Levels in Patients with Breast Cancer Who Received Chemotherapy}

To illustrate the relationship between menstruation status and hormones in these patients, we analyzed the data using logistic regression. As shown in Tables 2

Table 2 Menstruation Status in Breast Cancer Patients with Chemotherapy

\begin{tabular}{|l|l|l|l|}
\hline & Total & $<35 y$ & $\geq 35$ \\
\hline $\begin{array}{l}\text { Amenorrhea } \\
\begin{array}{l}\text { Menstruation } \\
\text { recovery }\end{array}\end{array}$ & II $28 / 144(77.8 \%)$ & $\begin{array}{l}8 / 20(40.0 \%) \\
\text { 6/8(75.0\%) }\end{array}$ & $\begin{array}{l}104 / 124(83.9 \%) \\
22 / 104(21.2)\end{array}$ \\
\hline
\end{tabular}


Table 3 The Relationship Between Menstruation and Reproductive Hormone (Logistic Regression Analysis)

\begin{tabular}{|c|c|c|c|c|}
\hline & \multicolumn{2}{|l|}{ Amenorrhea } & \multicolumn{2}{|c|}{ Menstruation Return } \\
\hline & OR (95\%) & $P$ value & OR (95\%) & $P$ value \\
\hline \multicolumn{5}{|l|}{ AMH } \\
\hline Pre-chemo & $0.3 \mid(0.157-0.6 \mid 2)$ & $<0.001$ & $0.224(0.079-0.631)$ & $<0.005$ \\
\hline Post-chemo & $0.319(0.167-0.61 \mathrm{I})$ & $<0.001$ & $0.161(0.053-0.484)$ & $<0.001$ \\
\hline \multicolumn{5}{|l|}{ Oestradiol } \\
\hline Pre-chemo & $0.983(0.873-0.994)$ & 0.002 & $1.003(0.99 \mid-1.015)$ & 0.637 \\
\hline Post-chemo & $0.980(0.969-0.991)$ & 0.001 & $0.985(0.973-0.988)$ & 0.023 \\
\hline \multicolumn{5}{|l|}{ FSH } \\
\hline Pre-chemo & $1.022(1.004-1.041)$ & 0.016 & $1.027(0.959-1.101)$ & 0.444 \\
\hline Post-chemo & $1.002(0.963-1.943)$ & 0.913 & $1.041(1.016-1.068)$ & 0.002 \\
\hline \multicolumn{5}{|l|}{ LH } \\
\hline Pre-chemo & $0.98 \mid(0.9 \mid 8-1.048)$ & 0.562 & $0.983(0.90 \mathrm{I}-\mathrm{I} .072)$ & 0.692 \\
\hline Post-chemo & I.0I I(0.972-I.052) & 0.578 & $0.981(0.947-1.015)$ & 0.266 \\
\hline
\end{tabular}

Table 4 Reproductive Hormone Levels in Breast Cancer Patients Before and After Chemotherapy (Wilcoxon Signed Ranks Test)

\begin{tabular}{|c|c|c|c|}
\hline & All & $<35$ & $\geq 35$ \\
\hline AMH (ng/mL) & & & $1.13(0.01,5.32)$ \\
\hline Pre-chemo & I.22 (0.0I, 8.68) & $3.29(0.81,8.68)$ & $0.97(0.01,4.02)$ \\
\hline Post-chemo & $\mathrm{I} .08(0.01,8.52)$ & $3.24(0.06,8.52)$ & \\
\hline P-value & $<0.001$ & 0.897 & $<0.0001$ \\
\hline \multicolumn{4}{|c|}{ Oestradiol (pg/mL) } \\
\hline Pre-chemo & $122.43(18,335)$ & $173.2(18,335)$ & II $9.44(27,242)$ \\
\hline Post-chemo & $63.88(5,287)$ & I34.7 (15, 287) & $64.56(5,234)$ \\
\hline P-value & $<0.0001$ & 0.361 & $<0.0001$ \\
\hline \multicolumn{4}{|l|}{ FSH (mlU/mL) } \\
\hline Pre-chemo & $|0.5|(1.32,83.22)$ & $8.30(1.55,38.82)$ & $10.54(1.32,83.22)$ \\
\hline Post-chemo & $51.22(3.45,121.06)$ & $30.82(3.56,119.83)$ & $51.82(3.45,121.06)$ \\
\hline P-value & $<0.0001$ & 0.014 & $<0.000$ I \\
\hline \multicolumn{4}{|l|}{ LH (mlU/mL) } \\
\hline Pre-chemo & $4.73(0.44,60.99)$ & $8.46(0.69,39.81)$ & $4.58(0.44,60.99)$ \\
\hline Post-chemo & $37.16(0.26,110.78)$ & $37.24(0.26,110.77)$ & $37.72(0.91,68.15)$ \\
\hline P-value & $<0.000$ I & $<0.0001$ & $<0.0001$ \\
\hline
\end{tabular}

Note: The data was described by mean, minimum, maximum.

and 3, chemotherapy-induced amenorrhea was significantly correlated with the prechemotherapy levels of $\mathrm{AMH}, \mathrm{E} 2$, and FSH and with the postchemotherapy levels of AMH and E2. The recovery of menstruation was significantly correlated with the prechemotherapy
AMH level, but not with that of E2 or FSH. This result indicates that, although amenorrhea may be predicted based on the prechemotherapy levels of AMH, E2, and FSH, menstruation recovery can only be predicted through the prechemotherapy AMH level. 
Table 5 Serum AMH Level in Normal Woman $(n=177)$

\begin{tabular}{|l|l|l|l|l|}
\hline \multicolumn{2}{|c|}{} & \multicolumn{3}{l|}{ AMH Level (ng/mL) } \\
\hline Age Group (yr) & N & Mean & Max & Min \\
\hline$<26$ & 6 & 3.61 & 8.04 & 1.56 \\
$26-34$ & 20 & 3.29 & 7.24 & 1.19 \\
$35-39$ & 26 & 1.58 & 5.32 & 0.31 \\
$40-44$ & 44 & 0.89 & 1.66 & 0.01 \\
$45-49$ & 45 & 0.36 & 1.18 & 0.01 \\
$50-54$ & 15 & 0.05 & 0.47 & 0.01 \\
$55+$ & 21 & 0.01 & 0.01 & 0.01 \\
\hline
\end{tabular}

Moreover, in patients with breast cancer treated with chemotherapy, the serum AMH and E2 levels did not differ significantly between the pre- and postchemotherapy periods in patients aged $<35$ years $(P>0.05)$, while a dramatic decrease in the levels of these hormones was detected postchemotherapy in patients $>35$ years $(P<0.0001)$ (Table 4$)$. These findings suggest that $\mathrm{AMH}$ levels are more effective in assessing chemotherapy-induced ovarian injury in premenopausal women older than 35 years.

\section{Trends of the Serum AMH Levels in Healthy Women and Female Mice, and Correlation Between Follicle Number and $\mathrm{AMH}$ Levels in Mice}

Next, we investigated the serum AMH levels in normal women of different ages. Table 5 displays the age distribution of all healthy women, as well as the median serum AMH levels according to age group. The serum AMH levels decreased sharply in women over 35 years of age $(P<0.0001$, Figure $2 \mathrm{~A})$ and were relatively stable prior to that age.

Subsequently, we further determined the serum AMH levels in C57BL/6J wild-type female mice of various ages. The serum AMH levels were increased in the younger mice and decreased significantly with increasing age (Figure 2B). We found three phases representing the changes in AMH levels. In the first phase, before 4 months of age, the serum AMH levels were obviously increased ( $\mathrm{r}$ $=0.97, P<0.0001)$. In the second phase, mice aged $4-8$ months exhibited relatively stable AMH levels $(r=0.97$; 4 vs 6 months of age, $P=0.28$; 4 vs 8 months of age, $P=$
A

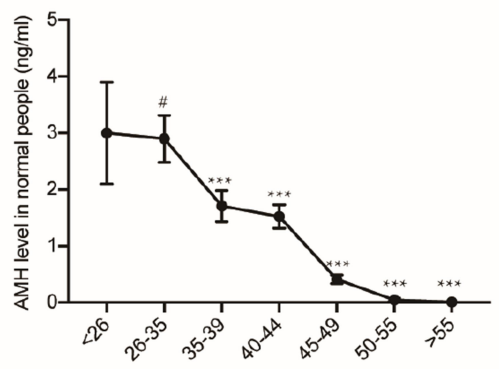

D

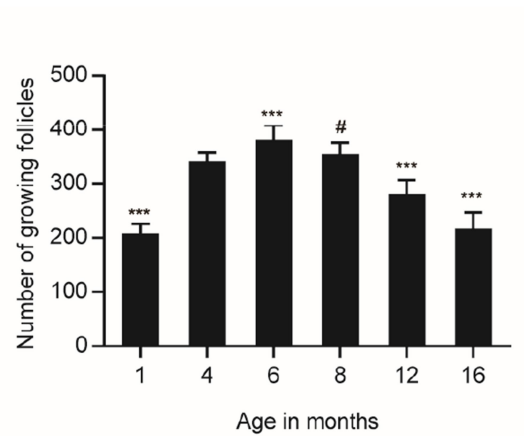

B

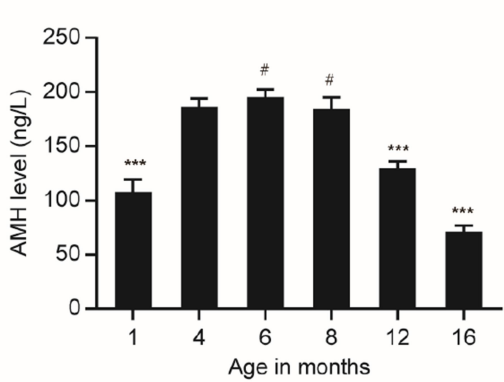

E

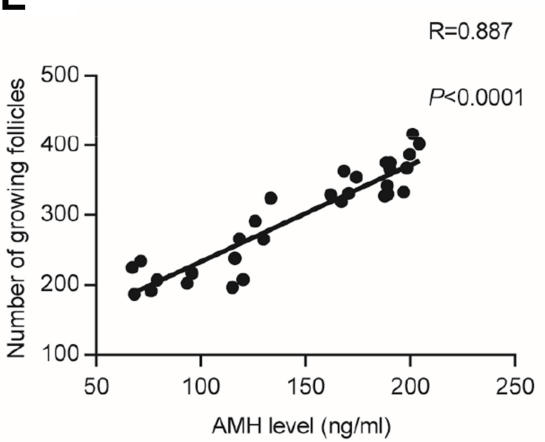

C

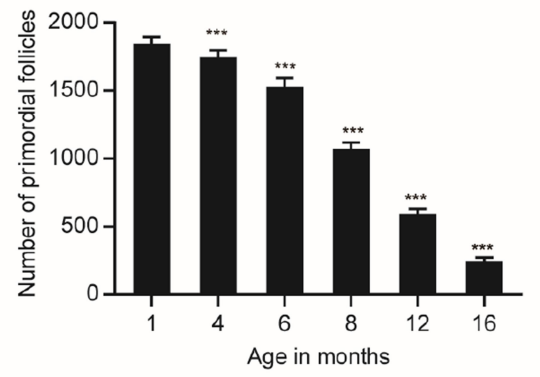

$\mathbf{F}$

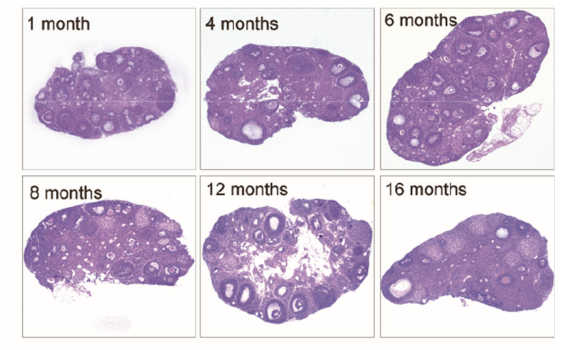

Figure 2 Trends of AMH levels in healthy women and female mice and correlation between follicle number and AMH level in mice. (A) The serum AMH levels were obviously decreased in women older than 35 years. (B) The serum AMH levels remained stable in 4-8-month-old mice, and were decreased after 8 months of age. (C) The number of primordial follicles decreased with increasing age. (D) The number of growing follicles was significantly decreased in mice older than 8 months. (E) The correlation between AMH levels and the number of growing follicles was strongly significant $(r=0.887, P<0.0001$, Pearson's test). (F) H\&E-stained ovaries from mice of different ages (B-D, each bar represents a minimum of six mice, ANOVA test).

\#, no statistical significance; $* * *, P<0.0001$ 
Table 6 The Correlation Between AMH Levels and Growing Follicles by Age Group

\begin{tabular}{|l|l|l|l|l|l|l|}
\hline $\begin{array}{l}\text { Age in } \\
\text { Months }\end{array}$ & $\mathbf{1}$ & $\mathbf{4}$ & $\mathbf{6}$ & $\mathbf{8}$ & $\mathbf{1 2}$ & $\mathbf{1 6}$ \\
\hline AMH level & 107.8 & 186.7 & 195.4 & 184.4 & 129.9 & 71.2 \\
(ng/mL) & \pm 11.6 & \pm 7.7 & \pm 7.1 & \pm 10.8 & \pm 6.1 & \pm 5.4 \\
Growing & 207.8 & 341.0 & 380.5 & 354.5 & 280.5 & 217.5 \\
follicles & \pm 16.3 & \pm 14.7 & \pm 24.7 & \pm 18.8 & \pm 23.5 & \pm 26.6 \\
\hline Pearson's & $\mathrm{r}=0.887, P<0.0001$ \\
correlation & \multicolumn{7}{|l}{} \\
\hline
\end{tabular}

0.98). A significant decline in AMH levels was observed in mice older than 8 months $(r=0.97, P<0.0001)$, an age at which mice had an irregular cycle and entered anestrus.

To confirm the relationship between AMH levels and ovarian reserve, the follicles of each mouse were counted. The results of this experiment revealed that the number of primordial follicles decreased with increasing age $(r=0.99$, $P<0.0001$; Figure 2C). Although the number of growing follicles increased before 6 months of age $(r=0.91, P<$ 0.0001; Figure 2D), it remained stable from 6 to 8 months of age $(r=0.91 ; 6$ vs 8 months, $P=0.21)$ and decreased significantly after 8 months of age $(r=0.91, P<0.0001)$. The histological appearance of the follicles is shown in Figure 2F. There was a strong correlation between the serum AMH levels and the number of growing follicles $(r=0.887, P<0.0001$; Table 6 and Figure 2E).

\section{Effect of Cyclophosphamide on Serum AMH Levels and Number of Follicles in Balb/c Nude Mice}

We found no significant difference in tumor size among the three groups before chemotherapy (Control vs CTX100 vs CTX200, $P>0.05$ ). The growth of tumors in the CTX $100 \mathrm{mg} / \mathrm{kg}$ group was similar to that observed in the control group, whereas tumor growth in the CTX $200 \mathrm{mg} / \mathrm{kg}$ group was slowed down more effectively (Control vs CTX200, $P<$ 0.0001). The trends of serum AMH levels and number of primordial follicles and growing follicles of Balb/c nude mice with breast cancer aged 8 weeks (prechemotherapy), 9 weeks ( 1 week after CTX or saline administration), 11 weeks ( 3 weeks after CTX or saline administration), and 13 weeks (5 weeks after CTX or saline administration) are shown in Figure 3A-C. The relationship between serum AMH levels and number of follicles in the control and CTX-treated groups is shown in Table 7. No significant differences in serum AMH levels were observed in the control group among mice aged 8-13 weeks, as well as among mice aged 8 weeks (prechemotherapy) in each group. In the $200 \mathrm{mg} / \mathrm{kg}$ CTX group, the serum AMH levels decreased significantly over time $(P<0.0001)$. Interestingly, in the $100 \mathrm{mg} / \mathrm{kg}$ CTX group, the serum AMH levels were increased slightly at 9 weeks of age, but decreased sharply at 11 weeks, followed by an eventual reincrease at 13 weeks of age. Moreover, the number of primordial follicles was consistently decreased over time in each group $(P<0.0001)$, whereas the downtrend was dramatic in the $200 \mathrm{mg} / \mathrm{kg}$ CTX group. The number of growing follicles always correlated with the changes in the serum levels of AMH. Changes in the number of growing follicles were identified using H\&E sections (Figure 3D).

\section{Discussion}

The extent of chemotherapy-induced ovarian damage is related to the patient's age, chemotherapeutic agent, drug regimen, and drug dose. ${ }^{30}$ Alkylating agents are the most gonadotoxic of the chemotherapeutic drugs, with toxicity decreasing in the order of platinum analogs, taxanes, plant alkaloids, anthracyclines, and antimetabolites, which are generally considered to be nongonadotoxic. ${ }^{31}$ Primordial follicles are more sensitive to cell-cycle-nonspecific agents, such as alkylating agents and topoisomerase inhibitors, while antimetabolites mainly affect the developing follicles, without altering the dormant follicle pool. ${ }^{30}$ In both human and mouse species, the decline in fertility is closely related to the reduction in the primordial follicle pool. Furthermore, cytotoxic drugs, particularly CTX, will cause the destruction of various follicles, particularly primordial follicles. ${ }^{32-34}$ The injury caused by CTX will eventually lead to ovarian dysfunction. It was reported that CTX injures the follicles in a direct way via DNA alkylation and subsequent disruption of normal cellular processes, and depletes the primordial follicles via the destruction of oocytes and granulosa cells. ${ }^{15,35}$ In the absence of AMH, ovarian follicle depletion was accelerated because of increased primordial follicle recruitment into growing follicles..$^{25,36}$

Although it has been reported that CTX-induced acute ovarian follicular destruction can not be predicted by serum AMH levels, ${ }^{25}$ according to our study, the occurrence of chemotherapy-induced amenorrhea was negatively correlated with the prechemotherapy levels of $\mathrm{AMH}$ and E2, and positively correlated with the prechemotherapy level of FSH level. In addition, the recovery of menstruation 1 year postchemotherapy was positively correlated with the pre- and post-chemotherapy levels of 
A

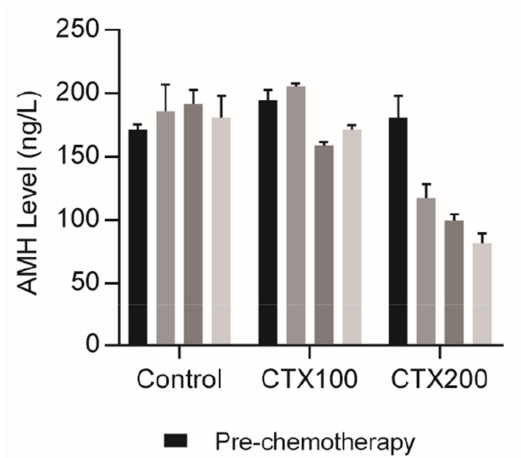

B

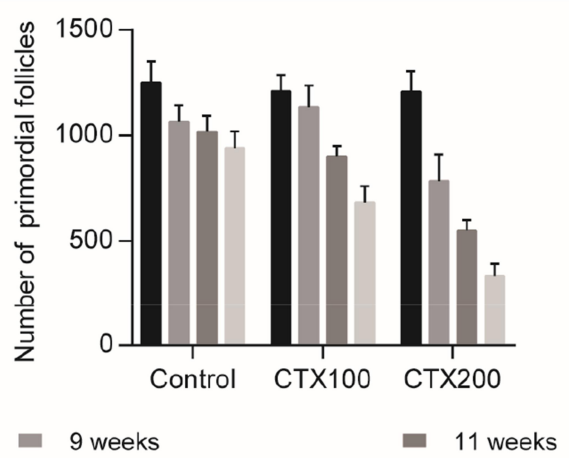

C

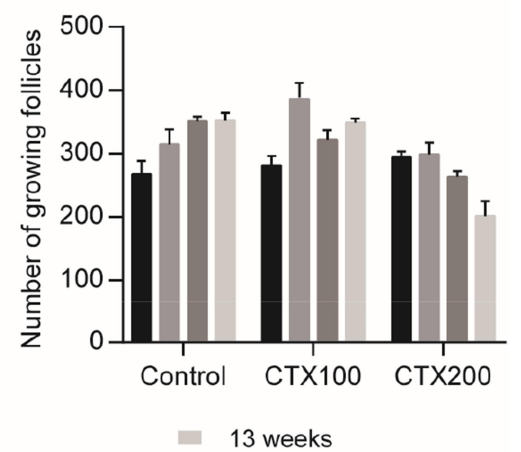

D

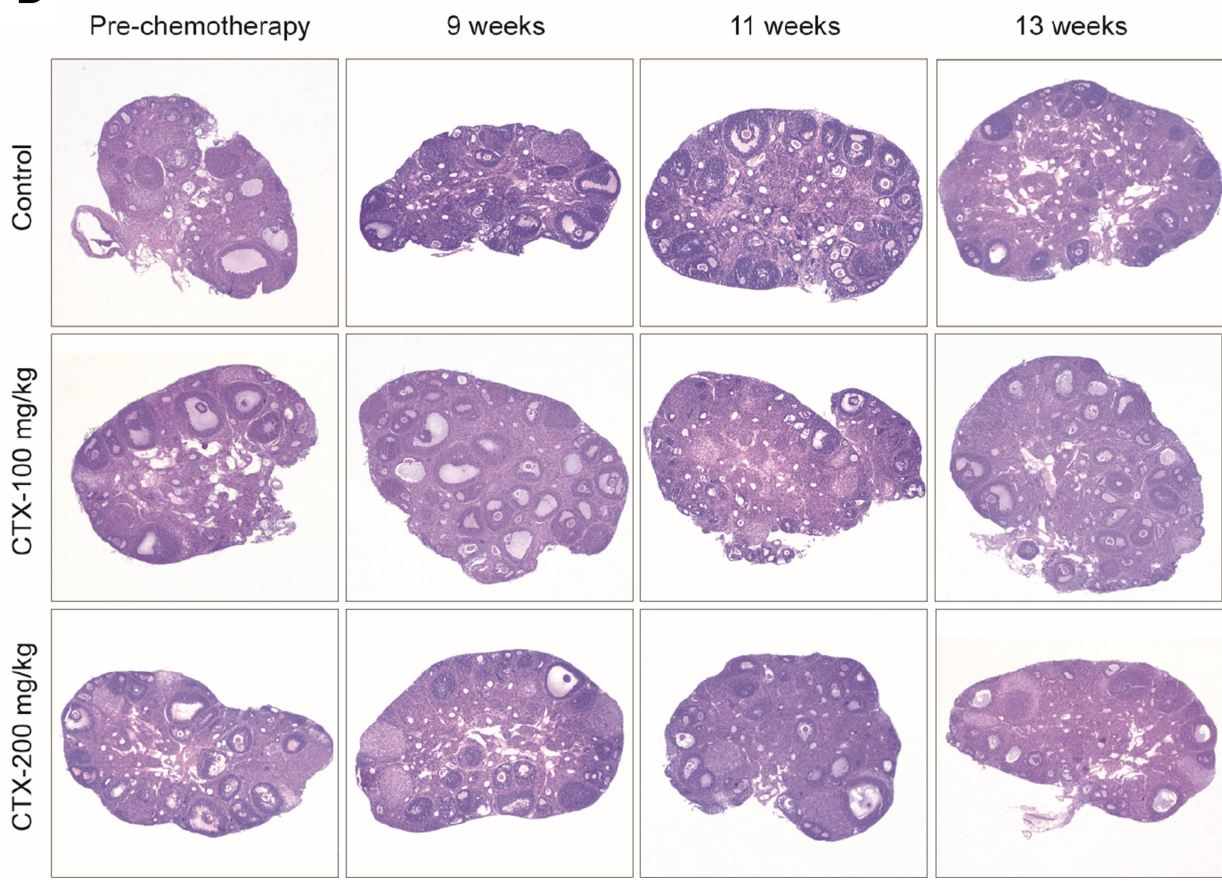

Figure 3 Serum AMH levels and number of ovarian follicles in Balb/c nude mice. (A) The serum levels of AMH remained stable in the control group, and were significantly decreased in the CTX $200 \mathrm{mg} / \mathrm{kg}$ group $(P<0.000 \mathrm{I})$. (B) The number of primordial follicles was not changed obviously in the control group $(P>0.05)$ and the $100 \mathrm{mg} / \mathrm{kg}$ CTX group at an early time point, while their decrease was apparent in the CTX $200 \mathrm{mg} / \mathrm{kg}$ group $(P<0.000 \mathrm{I})$. (C) The number of growing follicles remained stable in the control group and $100 \mathrm{mg} / \mathrm{kg}$ CTX group $(P>0.05)$. In contrast, it was significantly decreased in the $200 \mathrm{mg} / \mathrm{kg}$ CTX group at 5 weeks postchemotherapy $(P<0.000 \mathrm{I})$. (D) $\mathrm{H} \& \mathrm{E}$ staining of representative sections from all mice in the different treatment groups A-C each bar represents a minimum of six mice, ANOVA test).

$\mathrm{AMH}$, although it was not correlated with the prechemotherapy levels of E2 and FSH. These results imply that patients with higher AMH levels are less likely to have amenorrhea and more likely to return to normal menstruation, even postchemotherapy, whereas patients with lower AMH levels are more likely to have amenorrhea and less likely to recover menstruation after amenorrhea. ${ }^{24}$ Although the prechemotherapy E2 and FSH levels were correlated with amenorrhea, we did not find a correlation between them and menstrual recovery postchemotherapy, which was in line with our hypothesis; ie, that the levels of E2 and FSH fluctuate greatly along the physiological cycle, while the levels of AMH are relatively stable ${ }^{4}$. Further stratified analysis yielded interesting findings: in our clinical study, there were no significant changes in AMH levels in young patients who underwent chemotherapy, whereas AMH levels were dramatically decreased in patients over 35 years who received chemotherapy. ${ }^{37,38}$ Thus, in younger patients, a sufficient primordial follicle reserve and strong compensation ability resulted in stable AMH levels. Therefore, the serum AMH level as a biomarker for predicting ovarian function seems 
Table 7 The Comparison of AMH Levels and Follicle Numbers in Control and CTX-Treated Groups (ANOVA Test)

\begin{tabular}{|c|c|c|c|c|c|c|}
\hline \multirow{3}{*}{$\begin{array}{l}\text { Comparison } \\
\text { Time Point }\end{array}$} & \multicolumn{6}{|c|}{$P$ value } \\
\hline & \multicolumn{3}{|c|}{ GI vs G2 } & \multicolumn{3}{|c|}{ GI vs G3 } \\
\hline & AMH & PDF & GF & AMH & PDF & GF \\
\hline Pre-CTX & ns & 0.03 & ns & ns & ns & ns \\
\hline I week after CTX & 0.037 & ns & $<0.001$ & $<0.0001$ & 0.001 & ns \\
\hline 3 week after CTX & $<0.001$ & $\mathrm{~ns}$ & ns & $<0.0001$ & $<0.0001$ & $<0.0001$ \\
\hline 5 week after CTX & ns & 0.028 & ns & $<0.0001$ & $<0.0001$ & $<0.0001$ \\
\hline
\end{tabular}

Abbreviations: GI, control group; G2, CTX100 group; G3, CTX200 group; PDF, primordial follicles; GF, growing follicles; ns, not significant.

to be more accurate in women receiving chemotherapy older than 35 years compared with younger women $(<35$ years).

No consensus has been reached regarding whether $\mathrm{AMH}$ can be used as a predictor of ovarian function in women undergoing chemotherapy, especially in younger patients. ${ }^{37-}$

${ }^{39}$ Although studies have shown that AMH is of little value in predicting ovarian function in underage patients receiving chemotherapy, no reasonable explanation for this observation has been put forward. ${ }^{25,26,37,39}$ In our study of healthy women, the serum AMH levels exhibited a persistent decreasing trend with age in women over 35 years of age; however, it remained relatively stable in women younger than 35 years of age. Therefore, AMH may not be an accurate and suitable biomarker of ovarian reserve in younger women. ${ }^{40,41}$ We obtained a similar result in the mouse study, in which the serum AMH levels decreased with age in mice, after increasing over the first 6 months. The subsequent study revealed that the number of growing follicles was closely correlated with the number of primordial follicles and serum AMH levels. In mice older than 8 months, both the serum AMH level and the number of growing follicles decreased steadily, which is in accordance with the opinion of Scheffer et al. ${ }^{41}$ Moreover, in the mouse toxicity experiment, the number of primordial follicles was consistently decreased with time in each group $(P<0.0001)$, whereas the downtrend was dramatic in the $200 \mathrm{mg} / \mathrm{kg}$ CTX group. The number of growing follicles was always in accordance with the changes in serum AMH levels. The study reported by Luan et al found no significant increase in the number of mouse primary or secondary follicles; however, there was a significant increase in the ratio of growing follicles to dormant follicles after several cycles of CTX treatment. ${ }^{42}$ This may be attributed to the loss of dormant follicles, while the number of growing follicles remains the same. Correspondingly, a decrease in $\mathrm{AMH}$ serum levels was observed within 3 days after CTX administration, but these values returned to levels similar to those of vehicle-treated mice at 7 days posttreatment. ${ }^{42}$ These results suggest that, in immature female mice and women, $\mathrm{AMH}$ levels increase because of the increasing number of growing follicles. Subsequently, the number of growing follicles remains constant during the early reproductive period in females, accompanied by constant AMH levels. However, with increasing age, the serum AMH levels gradually decrease, which is accompanied by the decrease in the number of growing follicles in females.

$\mathrm{AMH}$ regulates the rate of primordial follicles recruited for further growth, and the recruitment of primordial follicles is inhibited by the presence of $\mathrm{AMH}$ in mature ovaries. ${ }^{4,7,36}$ In juvenile females because the follicles are mostly primordial follicles, AMH could not accurately evaluate the ovarian functional impairment. However, in young adults, even if the growing follicles were largely killed by the chemotherapeutic drugs, the remaining growing follicles and the timely replenishment of the primordial follicular pool maintained the stability of $\mathrm{AMH}$; thus, the serum AMH level did not accurately reflect the degree of damage of ovarian function. Conversely, AMH can accurately reflect the injury of ovarian function in middle-aged and elderly women because of their limited ovarian reserve. $^{40,43}$

\section{Conclusion}

According to our research, AMH is an effective biomarker for predicting the ovarian function in premenopausal female patients with breast cancer receiving chemotherapy, albeit exclusively in those older than 35 years. $\mathrm{AMH}$ as a predictor of ovarian function and an ovarian protectant is worthy of further study. ${ }^{18,29}$ Therefore, AMH may be used not only as a predictive and evaluating indicator of ovarian function in premenopausal female with multiple tumors, but also as a potential therapeutic target. 


\section{Abbreviations}

AMH, Anti-Müllerian hormone; MIS, Müllerian inhibiting substance; IVF, in vitro fertilization; PCOS, Polycystic Ovary Syndrome; CTX, Cyclophosphamide; POF, Premature ovarian failure; FSH, Follicular stimulating hormone; LH, Luteinizing hormone; E2, Estradiol; TNBC, Triple Negative Breast Cancer.

\section{Data Sharing Statement}

Any data intended for sharing is deidentified.

\section{Ethics Approval and Informed Consent}

The study was approved by the Institutional Research Committee, Animal Ethics and Welfare Committee of Shanghai Jiao Tong University affiliated Shanghai Sixth People's Hospital. All patients had given consent before enrollment.

\section{Acknowledgments}

We would like to thank all the clinical units and participants involved in this study. We would also like to thank FSeditor for the English language editing.

\section{Funding}

This project was funded by the Science and Technology Commission of Shanghai Municipality medical program 15411966500, and by Zhejiang Medical Society cancer research program 2015ZYC-A07.

\section{Disclosure}

The authors report no conflicts of interest in this work.

\section{References}

1. Cate RL, Mattaliano RJ, Hession C, et al. Isolation of the bovine and human genes for Müllerian inhibiting substance and expression of the human gene in animal cells. Cell. 1986;45(5):685-698. doi:10.1016/ 0092-8674(86)90783-X

2. Behringer RR, Finegold MJ, Cate RL. Müllerian-inhibiting substance function during mammalian sexual development. Cell. 1994;79 (3):415-425. doi:10.1016/0092-8674(94)90251-8

3. Josso N, Clemente N. Transduction pathway of Anti-Müllerian hormone, a sex-specific member of the TGF-beta family. Trends Endocrinol Metab. 2003;14(2):91-97. doi:10.1016/S1043-2760(03)00005-5

4. Kevenaar ME, Meerasahib MF, Kramer P, et al. Serum Anti-Müllerian hormone levels reflect the size of the primordial follicle pool in mice. Endocrinology. 2006;147(7):3228-3234. doi:10.1210/en.2005-1588

5. Weenen C, Laven JSE, Von Bergh ARM, et al. Anti-Müllerian hormone expression pattern in the human ovary: potential implications for initial and cyclic follicle recruitment. Mol Hum Reprod. 2004;10 (2):77-83. doi:10.1093/molehr/gah015
6. Behringer RR, Cate RL, Froelick GJ, Palmiter RD, Brinster RL. Abnormal sexual development in transgenic mice chronically expressing müllerian inhibiting substance. Nature. 1990;345 (6271):167-170. doi:10.1038/345167a0

7. Durlinger ALL, Gruijters MJG, Piet K, et al. Anti-Müllerian hormone inhibits initiation of primordial follicle growth in the mouse ovary. Endocrinology. 2002;143(3):1076-1084. doi:10.1210/ endo.143.3.8691

8. Wang S, Zhang Y, Mensah V, Huber WJ, Huang Y-T, Alvero R. Discordant anti-müllerian hormone (AMH) and follicle stimulating hormone (FSH) among women undergoing in vitro fertilization (IVF): which one is the better predictor for live birth? $J$ Ovarian Res. 2018;11(1):60. doi:10.1186/s13048-018-0430-z

9. Dewailly D, Laven J. AMH as the primary marker for fertility. Eur $J$ Endocrinol. 2019;181(6):D45-D51. doi:10.1530/EJE-19-0373

10. Garg D, Tal R. The role of AMH in the pathophysiology of polycystic ovarian syndrome. Reprod Biomed Online. 2016;33(1):15-28. doi:10.1016/j.rbmo.2016.04.007

11. Fredholm H, Eaker S, Frisell J, Holmberg L, Fredriksson I, Lindman H. Breast cancer in young women: poor survival despite intensive treatment. PLoS One. 2009;4(11):e7695. doi:10.1371/journal.pone. 0007695

12. DeSantis CE, Ma J, Gaudet MM, et al. Breast cancer statistics, 2019. CA Cancer J Clin. 2019;69(6):438-451. doi:10.3322/caac.21583

13. Rosenberg SM, Partridge AH. Management of breast cancer in very young women. Breast. 2015;24(Suppl 2):S154-S158. doi:10.1016/j. breast.2015.07.036

14. Sonigo C, Beau I, Binart N, Grynberg M. The impact of chemotherapy on the ovaries: molecular aspects and the prevention of ovarian damage. Int J Mol Sci. 2019;20(21):21. doi:10.3390/ijms20215342

15. Bedoschi G, Navarro PA, Oktay K. Chemotherapy-induced damage to ovary: mechanisms and clinical impact. Future Oncol. 2016;12 (20):2333-2344. doi:10.2217/fon-2016-0176

16. Broer SL, van Disseldorp J, Broeze KA, et al. Added value of ovarian reserve testing on patient characteristics in the prediction of ovarian response and ongoing pregnancy: an individual patient data approach. Hum Reprod Update. 2013;19(1):26-36. doi:10.1093/humupd/ dms041

17. Tal R, Seifer DB. Ovarian reserve testing: a user's guide. Am J Obstet Gynecol. 2017;217(2):129-140. doi:10.1016/j.ajog.2017.02.027

18. Steiner AZ, Pritchard D, Stanczyk FZ, et al. Association between biomarkers of ovarian reserve and infertility among older women of reproductive age. JAMA. 2017;318(14):1367-1376. doi:10.1001/ jama.2017.14588

19. Ulrich ND, Marsh EE. Ovarian reserve testing: a review of the options, their applications, and their limitations. Clin Obstet Gynecol. 2019;62(2):228-237. doi:10.1097/GRF.0000000000000445

20. Gracia CR, Shin SS, Prewitt M, et al. Multi-center clinical evaluation of the access AMH assay to determine AMH levels in reproductive age women during normal menstrual cycles. $J$ Assist Reprod Genet. 2018;35(5):777-783. doi:10.1007/s10815-018-1141-5

21. Dezellus A, Barriere P, Campone M, et al. Prospective evaluation of serum anti-Müllerian hormone dynamics in 250 women of reproductive age treated with chemotherapy for breast cancer. Eur J Cancer. 2017;79:72-80. doi:10.1016/j.ejca.2017.03.035

22. Fréour T, Barrière $P$, Masson D. Anti-müllerian hormone levels and evolution in women of reproductive age with breast cancer treated with chemotherapy. Eur $J$ Cancer. 2017;74:1-8. doi:10.1016/j. ejca.2016.12.008

23. Zhong Y, Lin Y, Cheng X, et al. GnRHa for ovarian protection and the association between amh and ovarian function during adjuvant chemotherapy for breast cancer. $J$ Cancer. 2019;10(18):4278-4285. doi:10.7150/jca.31859

24. Kim H-A, Choi J, Park CS, et al. Post-chemotherapy serum AntiMüllerian hormone level predicts ovarian function recovery. Endocr Connect. 2018;7(8):949-956. doi:10.1530/EC-18-0180 
25. Browne HN, Moon KS, Mumford SL, et al. Is Anti-Müllerian hormone a marker of acute cyclophosphamide-induced ovarian follicular destruction in mice pretreated with cetrorelix? Fertil Steril. 2011;96 (1):180-186.e2. doi:10.1016/j.fertnstert.2011.04.008

26. Detti L, Uhlmann RA, Lu M, et al. Serum markers of ovarian reserve and ovarian histology in adult mice treated with cyclophosphamide in pre-pubertal age. J Assist Reprod Genet. 2013;30(11):1421-1429. doi:10.1007/s10815-013-0087-x

27. Koga C, Akiyoshi S, Ishida M, Nakamura Y, Ohno S, Tokunaga E. Chemotherapy-induced amenorrhea and the resumption of menstruation in premenopausal women with hormone receptor-positive early breast cancer. Breast Cancer. 2017;24(5):714-719. doi:10.1007/ s12282-017-0764-1

28. Meirow D, Lewis H, Nugent D, Epstein M. Subclinical depletion of primordial follicular reserve in mice treated with cyclophosphamide: clinical importance and proposed accurate investigative tool. Hum Reprod. 1999;14(7):1903-1907. doi:10.1093/humrep/14.7.1903

29. Kano M, Sosulski AE, Zhang L, et al. AMH/MIS as a contraceptive that protects the ovarian reserve during chemotherapy. Proc Natl Acad Sci U S A. 2017;114(9):E1688-E1697. doi:10.1073/ pnas. 1620729114

30. Meirow D, Biederman H, Anderson RA, Wallace WHB. Toxicity of chemotherapy and radiation on female reproduction. Clin Obstet Gynecol. 2010;53(4):727-739. doi:10.1097/GRF.0b013e3181f96b54

31. Roness H, Kashi O, Meirow D. Prevention of chemotherapy-induced ovarian damage. Fertil Steril. 2016;105(1):20-29. doi:10.1016/j. fertnstert.2015.11.043

32. Kalich-Philosoph L, Roness H, Carmely A, et al. Cyclophosphamide triggers follicle activation and "burnout"; AS101 prevents follicle loss and preserves fertility. Sci Transl Med. 2013;5(185):185ra162185ra162. doi:10.1126/scitranslmed.3005402

33. Chen X-Y, Xia H-X, Guan H-Y, Li B, Zhang W. Follicle loss and apoptosis in cyclophosphamide-treated mice: what's the matter? Int J Mol Sci. 2016;17(6).

34. Sonigo C, Beau I, Grynberg M, Binart N. AMH prevents primordial ovarian follicle loss and fertility alteration in cyclophosphamide-treated mice. FASEB J. 2019;33(1):1278-1287. doi:10.1096/fj.201801089R
35. Nguyen QN, Zerafa N, Liew SH, Findlay JK, Hickey M, Hutt KJ. Cisplatin- and cyclophosphamide-induced primordial follicle depletion is caused by direct damage to oocytes. Mol Hum Reprod. 2019;25(8):433-444. doi:10.1093/molehr/gaz020

36. Durlinger AL, Kramer P, Karels B, et al. Control of primordial follicle recruitment by anti-Müllerian hormone in the mouse ovary. Endocrinology. 1999;140(12):5789-5796. doi:10.1210/ endo.140.12.7204

37. Decanter C, Morschhauser F, Pigny P, Lefebvre C, Gallo C, Dewailly D. Anti-Müllerian hormone follow-up in young women treated by chemotherapy for lymphoma: preliminary results. Reprod Biomed Online. 2010;20(2):280-285. doi:10.1016/j. rbmo.2009.11.010

38. van Beek RD, van den Heuvel-eibrink MM, Laven JSE, et al. AntiMullerian hormone is a sensitive serum marker for gonadal function in women treated for Hodgkin's lymphoma during childhood. J Clin Endocrinol Metab. 2007;92(10):3869-3874. doi:10.1210/jc.20062374

39. Lutchman Singh K, Muttukrishna S, Stein RC, et al. Predictors of ovarian reserve in young women with breast cancer. $\mathrm{Br} J$ Cancer. 2007;96(12):1808-1816. doi:10.1038/sj.bjc.6603814

40. Wong QHY, Anderson RA. The role of antimullerian hormone in assessing ovarian damage from chemotherapy, radiotherapy and surgery. Curr Opin Endocrinol Diabetes Obes. 2018;25(6):391-398. doi:10.1097/MED.0000000000000447

41. Scheffer GJ, Broekmans FJM, Looman CWN, et al. The number of antral follicles in normal women with proven fertility is the best reflection of reproductive age. Hum Reprod. 2003;18(4):700-706. doi:10.1093/humrep/deg135

42. Luan Y, Edmonds ME, Woodruff TK, Kim S-Y. Inhibitors of apoptosis protect the ovarian reserve from cyclophosphamide. J Endocrinol. 2019;240(2):243-256. doi:10.1530/JOE-18-0370

43. Bozza C, Puglisi F, Lambertini M, Osa E-O, Manno M, Del Mastro L. Anti-Mullerian hormone: determination of ovarian reserve in early breast cancer patients. Endocr Relat Cancer. 2014;21(1): R51-R65. doi:10.1530/ERC-13-0335
Cancer Management and Research

\section{Publish your work in this journal}

Cancer Management and Research is an international, peer-reviewed open access journal focusing on cancer research and the optimal use of preventative and integrated treatment interventions to achieve improved outcomes, enhanced survival and quality of life for the cancer patient.
Dovepress

The manuscript management system is completely online and includes a very quick and fair peer-review system, which is all easy to use. Visit http://www.dovepress.com/testimonials.php to read real quotes from published authors. 